\title{
MUJER E IDEOLOGÍA EN EL CÁDIZ ISABELINO: LAS CORRIENTES DE VANGUARDIA
}

\section{JOSÉ MARCHENA DOMÍNGUEZ Universidad de Cádiz}

La actitud ideológica de los núcleos republicanos, fuertemente influenciados por las corrientes utópicas francesas, generó a lo largo del segundo tercio del siglo XIX una doctrina peculiar que influyó igualmente en la consolidación de un proyecto político durante la España isabelina. Esto es, junto a la creación y desarrollo del Partido Demócrata Republicano, se fue cimentando una visión de la vida en sus aspectos sociales y económicos más sobresalientes, entre los que se incluyó con cierta preferencia el tema de la mujer. Las alternativas y matices en torno a tan novedoso asunto para la época, quedaron plasmadas en los testimonios periodísticos del Cádiz isabelino-objeto de este estudio-, como testigos en el tiempo de una reivindicación innovadora.

En este sentido, y en aras de establecer un orden, dividimos tres grandes bloques o secuencias de opinión sobre la mujer: un primer periodo que coincide con la llegada de Abreu y el desarrollo de las ideas fourieristas a la provincia gaditana, junto a otros teóricos como Ambrosio Grimaldi. Un segundo momento que pendula entre problemas con la prensa y la coyuntura favorable de O’Donnell y la «Ley Cánovas», y que asiste a la creación de hasta dos títulos referentes a las nuevas corrientes feministas, en donde aportan su opinón demócratas como José Bartorelo o Roberto Robert. Por fin el último en la encrucijada de la «Gloriosa Revolución» de 1868, donde localizamos una teoría del rol social de la mujer elaborada por un joven Fermín Salvochea.

\section{La llegada de Abreu y los inicios reivindicadores feministas.}

La irrupción en Francia de las corrientes llamadas premarxistas o utópicas, consistentes en una nueva visión socioeconómica de la Europa postrrevolucionaria, origina la puesta en tela de juicio de una serie de conceptos hasta ahora casi indiscutibles; un de ellos fue el tema de la mujer. En 1837 y en su libro Théorie des quatre mouvements, el ideológo Charles Fourier, utilizaba por vez primera -según sostiene Karen Offen- el término «feminismo», como el punto de partida a una ruptura de la dependencia económica de la mujer y su emancipación del hombre. Esta concepción que pasaba a tener cabida en su modelo de «atracción pasional universal», arraigó también en otro teórico de este grupo socialista: Saint-Simón y seguidores como Chevalier o Enfantin, que reivindicaron el feminismo por los años veinte o treinta, en forma de grupos de corte católico donde se planteaban la actitud pública de la mujer como un paso de la «fuerza bruta» imperada por el hombre, a otro tipo de «poder espiritual» (1).

La fecha de 1835 marcó el regreso del exilio de Francia, del político tarifeño Joaquín Abreu y Orta (1782-1851) y con él, la irrupción del fourierismo 
en Cádiz y su provincia a través de prensa y militancia, gracias a las doctrina asimiladas en su aprendizaje con Fourier.

Sin entrar en la mayor o menor influencia de Abreu en el concierto utópico español, anotamos la creación de un primer núcleo o escuela donde ya en cierta medida, notamos cierta permeabilidad de las concepciones feministas, al formar parte de éste la aristócrata jerezana Joaquina de Morla (2).

El 9 de enero de 1841 y en las páginas del periódico progresista $\underline{\mathrm{El}}$ Nacional -uno de los más prolijos en escritos de Abreu- aparece un artículo del precursor del fourierismo gaditano, perteneciente a una serie que bajo el título genérico de «Fourier», venía realizando desde hacía justo un año, con el fin de dar a conocer pormenorizadamente la teoría del ideólogo francés. En particular éste que hacía el número nueve de la colección, se refería a la situación social de la mujer. Al igual que Saint-Simon, Abreu pensaba que la sociedad relegaba a la mujer a un dependencia económica y vital respecto al hombre. De tal manera, la mujer se mediatiza exclusivamente para el martrimonio y una vez logrado, cubrir todas las labores no remuneradas del hogar. El hombre ha de mantenerla y por lo tanto, «...se establece la dependencia del que recibe y el dominio del que da», todo ello, fruto del cuestionable esquema familiar:

«La organización de la familia es mala; lo es porque sobre el padre recae el peso de sus alimentos; lo es porque la madre no tiene libertad ni medios de adquirir; lo es porque sus hijos son educados como las madres; y los hijos aprenden el oficio del padre, las más veces en oposición con sus inclinaciones; lo es en fin, porque sólo la violencia contiene los gérmenes de discordia que en la familia existen.»

Ante tal situación, Abreu aporta la solución fourierista del falansterio, como ámbito idóneo para lograr los requisitos de «atracción pasional»; es decir, todos participan del colectivo, eligiendo libremente la pareja y el trabajo y ello, sin ningún tipo de orden establecido o «moral». Aquí, la mujer tiene libertad e independencia para desarrollar sus facultades materiales e intelectuales y su propia subsistencia; «ya no es el matrimonio su único destino, sino que lo mira como el hombre; primero vivir y luego casarse» (3).

Justo en las mismas páginas de El Nacional y once meses más tarde, el también fourierista y demócrata Ambrosio Grimaldi, escribe un conjunto de tres artículos sobre la mujer. Grimaldi, al igual que su correligionario Abreu, critica la relación hombre-mujer y no sólo la tacha de opresiva, sino que teoriza de defecto en el tiempo, considerando tal relación como una ley de naturaleza que ha dominado hasta las «cabezas más ilustradas»; «los hombres -apunta- se equivocan con frecuencia sobre los designios de la naturaleza, que la duración de los abusos por muchos siglos prueba [...] la costumbre, la indolencia y la ignorancia del hombre [...] empezando por las religiones, siguiendo por la política y concluyendo por las costumbres, los siglos han consagrado los mayores absurdos, contrarios a la naturaleza.» 
La mujer sufre las secuelas de los propios elementos culturales y consuetudinarios de cada colectivo. De tal forma, en cada zona sus padecimientos son variables, pues si en un estado natural de origen, hombre y mujer parten de un mismo punto, la evolución y la civilización los separan paulatinamente de destinos.

Así se pasa de una mujer «animal doméstico» en oriente a través de los harenes, a otra mujer más desahogada en el norte con sus labores y de otra con amplias prerrogativas en el mediodía qué teniendo «toda la libertad neceșaria para hacer el mal, no tienen la educación conveniente para hacer el bien», en clara alusión al estereotipo de «vampiresa femenina» presa de su rol social, que no hace sino lo que el corrupto modelo social le posibilita hacer. De esta forma la crítica fourierista a la célula familiar burguesa, describe a una mujer acomodada con ciertos conocimientos de Gramática, Geografía, Baile y Música, y con una irresistible soberanía y «...más influencia que ninguna en los negocios públicos y llegan muchas veces hasta el mismo trono». Dulzuras, encantos, súplicas, zalamerías. Matices recogidos de la huerta de una sociedad burguesa de valores trasnochados y aparentes, que hacen de la mujer exponente típico de este desajuste:

«Se oye el toque de generala a media noche, y una mujer pone las correas a su marido, otra arranca el fusil al suyo y el hombre, balanceando entre sus deberes de familia y los de la patria, cede muchas veces a la súplica, a la compañera de sus amores que le rodea presentándole sus hijos...»

Las perspectivas y objetivos marcados por Grimaldi en cuanto a la misión de la mujer en la revolución social, se las promete felices: deseo de utilidad moral y política de la mujer para «...recobrar a través de las costumbres su perdido imperio». Sin embargo, las conclusiones finales no pasan de una mera aspiración laboral de la mujer en trabajos muy contados -de tipo manual y artesanal- y resaltar lo que considera cualidades innatas en el sexo femenino, y diferentes al masculino:

«No por esto se crea que queremos establecer una extravagante igualdad entre las facultades y deberes de los dos sexos. La naturaleza ha señalado las cualidades y límites de cada uno. A la mujer ha concedido la belleza, la sensibilidad, el sufrimiento y la astucia: al hombre la fuerza, el valor y el talento público que abraza a la vez todas las relaciones del mundo material, moral y político. Pero negamos que se haya dado al hombre el imperio exclusivo del mundo; y creemos que es un abuso de su fuerza y un error de su entendimiento reducido, la esclavitud de la mujer. Donde quiera que las costumbres o la necesidad han dejado a la mujer la libertad, se la ha visto prontamente elevarse al nivel del hombre en cuanto lo ha permitido la delicadeza de sus órganos» (4): 


\section{Años cincuenta y sesenta: de los «Pensiles» a «La Buena Nueva».}

Estas ideas propugnadas por los socialistas premarxistas desde hacía dos décadas, no cayeron en saco roto. Durante este periodo aparecieron en el espacio nacional -y ésta fue la novedad- publicaciones dirigidas por mujeres y esporádicos reflejos en la prensa sobre reivindicaciones del voto femenino. Todo ello, emanado de un núcleo de mujeres en Cádiz que al menos desde 1856, elaboraron una saga de periódicos que bajo el título genérico de «El Pensil», se considera la primera revista feminista de España (5).

Sin entrar excesivamente en el contenido y desarrollo de la revista, resaltamos la influencia fourierista con la variante de Toussenel que según Elorza, posibilitaba el discurso de esta nueva concepción feminista, en la dimensión romántico-amorosa del XIX, y en una onda «espiritista»: variante del fourierismo, pero que justifica la teoría del francés, en las relaciones hombreDios-Cosmos.

En «El Pensil», no perdieron comba los hombres jóvenes del recién creado Partido Demócrata, caso de Francisco Pi y Margall, Roberto Robert, Roque barcia, Fernando Garrido y José Bartorelo. Este último más prolífico y vinculado al núcleo de escritores gaditanos.

En el número del 20 de febrero de 1858, se recogía un artículo del propio Fourier sobre su opinión en torno a la mujer. De inicio culpaba al propio sistema social que comprimía a la mujer sus facultades, desde la infancia hasta el final de su vida. No era por lo tanto culpa suya -opinaba- de la inferioridad de preparación que presentaba respecto al hombre, demostrando su superioridad sobre éste, cuando les había sido posible caso de las reinas. Y esta superioridad podría ser demostrada totalmente en el futuro «...en todas las funciones del espíritu y de cuerpo.»

Por otra parte, José Bartorelo en buena óptica fourierista, expresaba su rechazo por el matrimonio considerándolo un engaño. Argumenta la falta de amor con que se hacen todos los casamientos, tanto ricos como pobres; «...poco tiempo después de su unión, dejan de verse los esposos con ojos de amor, y el engaño es tanto más grande, cuanto más viva y ciega ha sido la pasión.»

Llega a calificar la realidad matrimonial como una transacción comercial de intereses mútuos (dotes), aunque menos en los pobres. Estos intereses a la postre eran ajenos al amor y a la pasión humana que a diferencia de la animal, «es a la vez sensitiva, afectiva e intelectual, y comprendiendo los actractivos de sensación, de sentimiento de inteligencia o de razón y pudiendo alcanzar la conciencia clara de su destino.»

Es también de destacar la traducción libre realizada por Bartorelo de la medium norteamericana A. J. Davis, pronunciada en la Sociedad «Great Harmony» y que publicaba bajo el título «revelación del Universo natural, 
espiritual y celeste», reincidía en una reivindicación social de la mujer, ante un hombre que ha degradado desde siempre su valor y su condición. Especifica como la mujer de clase rica -mujer de élite-comienza a huir de esta tendencia. No obstante reconoce que entre el hombre y la mujer hay una diferencias físicas y morales:

«Aún en la Europa y América cristianas [...] cuesta trabajo considerar a la mujer como una compañera del hombre [...] la general opinión con respecto a la mujer es aún una especie de máquina, hecha para regalo y satisfacción del hombre: casarse, tener hijos.»

Bartorelo apunta cómo la mujer, detentadora de la conservación y mantenimiento de la prole, debe ser garantizada por la sociedad, con una relación matrimonial, buena y cómoda, lo que a la postre inserta este modelo teórico en el puro y duro círculo doméstico:

«...según es la organización y educación del espíritu femenino, así será el hogar doméstico que presente al esposo e hijos [...] ella desplega suma gracia y facilidad para el desempeño de sus varias domésticas vocaciones..»

Tras la bíblica alusión de una mujer costilla del hombre, y por lo tanto parte integral e igual a éste, enumera las reivindicaciones básicas, a saber:

«1: una justa representación de sus intereses/2: buenas relaciones matrimoniales/ 3: completa educación/ 4: armoniosa situación social y local/ 5: consejos, no mandatos; admiración, no adulación/6: honras, no patrocinio; pura sabiduría, no falseamiento o contrahechuras de la verdad.»

Finalmente, condiciona el éxito de estos postulados a «los resultados de la reorganización social, y de un gobierno universal armónico.»

Por último, Bartorelo, a la vez que traducía las ideas fourieristas de Davis, escribía entre otras cosas lo desagradable del desarollo del niño y el adolescente en su núcleo familiar, corrupto y maestro de todos sus vicios intrínsecos. También de su cosecha, escribía en verso lo siguiente:

«Por qué impedir que tus pasiones vuelen/ a proporción de tu vital destino?/ por qué el varón en su arrogancia loca/ se cree del globo el director más divo?/ que tu cerebro vale/ sin tu soplo divino?/ El reinado de Dios está delante,/ y preñado de un mundo de delicias/ para todos radiante./ Ora, mujer, si aún no lo has merecido:/ ora, y pide al señor con fe constante,/ venga a más el tu reino prometido (6)».

También el republicano catalán Roberto Robert manifestaba sus razones en pro de la igualdad femenina, a través de su artículo «La educación de la Mujer». Habla del error de haber destinado a la mujer en sociedad, a un fin inferior al que el propio Dios y la naturaleza le había enseñado. También insiste 
en la función y dedicación al hijo, intrínseca a la mujer y que por fortuna, «...el hombre no ha dado aún en la manía de monopolizar esta misión, gracias a que le parece indigna o quizás poco gloriosa.»

Al igual que Bartorelo en su comentario de Davis, se lamenta de la incultura y ausencia del papel de muchas mujeres en el seno familiar, trayendo consigo irregularidades en la convivencia. Para esto, Robert postula que al menos dentro de cada casa, se debía plantear una remodelación de la mujer, ese progreso que la haga un ser más de la casa, con su función y su educación (7).

Posteriormente y ya entrada la década de los sesenta, el grupo fourierista gaditano publica otra revista que pos título La Buena Nueva saca a la luz varios ejemplares en 1866, tras diversos intentos de buscar un continuador a a quella saga de «los Pensiles». Si bien el grupo de partida fue básicamente el mismo Zapata, Celis, Bartorelo-, a los problemas de publicación y de costos, se les suma la marcha de algunos viejos colaboradores demócratas como Garrido o Pi y Margall. No obstante los postulados de defensa del fourierismo, democracia y feminismo,siguieron en las líneas de la nueva revista. Caso de Bartorelo, que en su «Misión de la pareja humana», insiste en la infracción que supone al designio divino del creador la situación de la mujer, y su necesidad de pronta regeneración en un movimiento de armonía universal:

«La mujer, este último esfuerzo del creador, como coronamiento de su obra, después que sumergió a Adán en un sueño profundo, y al despertar se encontró con su manifestación femenina, en cuya delicada estructura [...] apenas el suelo tocan [...] y que suerte le ha deparado al hombre al hacerse dueño de la legislación y el poder? La esclavizó, la privó de todos sus derechos, a la entrada en ningún cargo público, en el ejercicio de ningún ramo de industria, pues la relega a los simples y exclusivos quehaceres de la maternidad [...] pero cuando las oleadas se precipiten entonces presenciaremos la segunda venida del Mesías, cuando el hombre y la naturaleza entren otra vez en la armonía, el uno con la otra y ambos con Dios» (8).

\section{Fermín Salvochea y la «Revista Gaditana».-}

A pesar de los intentos de apertura de los gabinetes Narváez y GonzálezBrabo, lo cierto fue que la sublevación de sargentos en el Cuartel de San Gil, aceleró el establecimiento por parte del primero, de un estado de Excepción que suspendía a la vez las garantías constitucionales. Los periódicos progresistas y demócratas fueron suprimidos y en especial durante el último gobierno antes de «La Gloriosa», la prensa fue perseguida por vía legal.

Los escasos títulos con participantes demócratas o bien eran clandestinos, o bien se escudaban bajo artículos literarios sin compromiso ideológico aparente. 
En 1867 y bajo la presión descrita, nacía la Revista Gaditana, periódico de carácter literario, cultural y científico, donde colaboraron entre otros demócratas Narciso Campillo, Ambrosio Grimaldi, Pedro Canales, José Sanz, Buenaventura Abarzuza y Fermín Salvochea. Este último desarolla a lo largo de diecisiete artículos, toda una crítica al modelo social influido ppor las concepciones ilustradas y utópicas de Cabet y Owen, en cuanto a considerar al hombre bueno por naturaleza, pero alterado por el mal funcionamiento de la sociedad.

Lógicamente, uno de los grandes bloques de crítica social lo encomendó al dualismo hombre-mujer. Su planteamiento de crítica a la inferioridad femenina ante un varón que la esclaviza, coincide con las ideas desarrolladas por la escuela fourierista. No obstante, en contra de lo que solían escribir éstos, de un modo serio y objetivo, Salvochea rompe esta dinámica, optando por unas maneras más irónicas y sarcásticas, describiendo situaciones imaginarias y ridículas, que a la postre venían a decir todo lo contrario. No obstante en temas tan dramáticos como la prostitución, la seriedad hace presencia obligada en los escritos del gaditano:

«Niégase a una infeliz huérfana los [...] recursos para vivir pero [se le muestra como] un Edén el camino de la prostitución. ¡Es tan fácil engañar a una inocente abandonada! [...] la lucha es desigual y la joven queda vencida [...] al vil seductor la sociedad le alarga la mano, cubriendo el delito..» (9).

Se plantea en primer lugar un muestreo real de los papeles asignados para el hombre y la mujer que generan unos comportamientos concretos, con una impronta de exageración por parte del articulista, concediendo «al hombre la fortaleza [...] para [ellas] la belleza y la debilidad [...] la sola definición de los dos sexos envuelve un principio reprobado por la sana razón, y sin embargo sirvió de base al edificio social [...] la sociedad ha hecho de cada hombre un maniquí» (10).

Tal cantidad de «poderes femeninos» -como también desarrolla Grimaldi recordamos- justifica en el hombre una actitud de control y dominio a la mujer deseando «tengamos al bello sexo en nuestro favor», o bien suprimiendo sus mejores armas «...que ni mienta ni enrede, ni murmure, ni tenga visitas, ni pida dinero $[\ldots .$.$] un collar sin cascabeles.»$

En un plano más desenfadado, asigna un nuevo rol al papel social de la mujer con proposiciones feministas, graciosamente intercambiadas con el hombre:

«La mujer en el nuevo orden social [...] no tendría esa importancia que ella misma ha querido darse. Deber suyo será correr tras el amante [...] rondar día y noche la calle de su futuro señor y dueño, darle serenatas, declararle su pasión y batirse [...] para atrapar un marido» (11). 
Varias son las comparaciones y símiles a los que Salvochea les somete. Así, de llamarla «capitana generala», pasando por ser una planta que pendula desde la belleza temprana hasta la mustiedad.

Dentro de un hipotético contexto parlamentario, ridiculiza su papel tradicional de objeto:

«QQue gusto dará ver a trescientas mujeres discutiendo los presupuestos para que nada les falte [...]

-Que hay una declaración de guera.

-Como una de amor, sobre poco más o menos.

-Un pienso al caballo de batalla, y brida en mano.

-Que se acercan doscientos mil rusos a la frontera.

-Bien ¿y qué? doscientas mil mujeres sobre la frontera y sobre los rusos. Sorprendamos a la diplomacia el más importante de sus secretos, el de jugar sin perder.

-Que caen los rusos prisioneros. Claro que es que ganamos.

-Que cargan los rusos con las doscientas mil mujeres. Feliz viajes y que escriban Vds. en llegando. Quedamos en paz» (12).

Queda también ridiculizado su ideal estético, personificado por un ejército de mujeres de años entrados, que reivindican la derogación de ser el «feo sexo» a un periódico -la propia Revista Gaditana-. La cabecilla se va despojando de pelucas y rellenos hasta que descubre ser «una suegra». Es éste sin duda el personaje del microcosmos femenino, más castigado por Fermín Salvochea, viendo en ella símbolos y exponentes del viejo esquema social, trasnochado e inservible.

Amén de compararla burlonamente con una tarántula venenosa, un gallo de pelea o una enfermedad, le asigna unas funciones concretas en el cosmos social:

«Su misión sobre la tierra es servir de guerilla en las primeras escaramuzas de amor, de guardia de honor en el casamiento y de tribunal supremo en las querellas matrimoniales [...] deben gozar, sin contribución industrial ni de comercio, todos los fueros y privilegios concedidos al bello sexo de que forma parte» (13).

A su parecer, la solución a este «problema», como todo lo referente al esquema egoista y degradante de la familia monogámica en buena lógica fourierista, pasaría por una desaparición integral de la misma. Esta solución de ruptura, pasa también por la que asocia a la suegra como fin y objeto primordial: ser catalizadora del emparejamiento amoroso.

El pretendiente de turno no puede evitar el temer «...a una de esas señoras antediluvianas; de esas señoras que nunca han sido jóvenes ni nunca quieren ser viejas que [...] las vemos nosotros, las vieron nuestros padres y las vió Noé a su 
salida del Arca [...] monumentos históricos que [...] caja de truenos [...] guarda en conserva para aterrar a los desdichados amantes». Al final el pobre varón ha tenido que pasar por los suplicios y exigencias sociales con el amor, y además de gastos y más gastos desde el primer contacto hasta la boda, contrae varios síntomas crónicos:

«Náuseas al fijar la vista en una mujer que pase de cuarenta años; desvanecimiento de cabeza al oir hablar de matrimonio; risa convulsiva si se presencia el entierro de una vieja y [...] el bolsillo como cañón de órgano» (14).

Efectivamente la economía, caballo de batalla social de primera mano, es criticada por Salvochea en otras variantes que atañen al asunto de la mujer como los bienes inmuebles o la institucionalización de la dote-como también sostiene Bartorelo. Si por un lado «...las casas de los pobres no son buenas, y como la sociedad no ofrece más que lo bueno..», por otro «...el empuje de una suegra [está] en razón directa de la dote de la niña [...] porque el ídolo del mundo es el dinero» (15).

\section{Conclusiones.}

Apuntamos el debate ideológico desarrollado sobre la mujer en el núcleo fourierista-demócrata gaditano, como básico y fundamental para comprender las tesis del feminismo y el desarrollo del aintegración de la mujer en el protagonismo social burgués. Sin embargo, no olvidar que si bien la mayoría de estas teorías de raiz fourierista parten de una absoluta conciencia de las carencias, injusticias y vejaciones a que son sometidas, en última instancia el concepto de doble moral sexual, a tenor de la realidad y del protagonismo socioeconómico burgués del varón, es dominante; lo que inicialmente supone la ruptura de la base organizativa mayor -sociedad de clases- y menor -matrimonio-, no hace a la postre sino intentar amoldarse a la mentalidad imperante: la mentalidad burguesa.

Así se intenta por encima de todo, una mayor dignificación en el cumplimiento de la mujer como madre y esposa y no una revolucionaria transformación laboral e intelectual de ésta. A lo más una mayor cualificación en su grado, de aquellas mujeres insertas en cuadrso de élite -téngase en cuenta que las mujeres protagonistas de estas revistas pioneras, son de clase media y defienden el honor como símbolo y garantía de su aprecio y estima social.

No obstante y salvando las correspondientes consideraciones, se corrobora una influencia del feminismo en el espacio gaditano, pues a las citadas publicaciones y contenidos afines, se suman las iniciativas de alunos correligionarios, caso de la «Sociedad de Liceo Gaditano» fundada por Manuel Sagrario de Beloy y José Sanz en 1855; círculo destinado a las artes y la cultura, donde se exigían socios «...honrados y de educación, de ambos sexos», rogándose acudir a éstas sin lujos. 
De esta manera, los principales trtadistas del asunto como Abreu, Grimaldi, Bartorelo o Robert, partían de esquemas armónicos y universalistas según los planteamientos de Fourier, para perderse y esfumarse luego en proposiciones de leves mejoras. Más radical y mordaz nos parece el caso de Salvochea en sus planteamientos, pues a su más comprometida y pormenorizada crítica social del hombre y la mujer sumamos el ejemplo de su propia vida, rompiendo con sus orígenes burgueses y conectando posteriormente con posiciones obreristas.

\section{NOTAS.}

(1) V. OFFEN, K., «Sur l' origine des mots «Féminisme» et «Féministe», Revue d' Histoire Moderne et Contemporaine, París, jul. sept. 1987, pp. 492-496, y MOSES, C.G., «Saint Simonian men/Saint Simonian women: the transformation of Feminism thought in 1830' s France», The Journal of Modern History, Chicago, vol. 54, jun. 1982, pp. 240-267.

(2) Morla es una de las activistas, junto a Pedro Luis Huarte o José Bartorelo, que introducen las nuevas ideas en el espectro gaditano, a través de tradicciones de teóricos afines. Concretamente Morla traduce y publica en Cádiz en 1841 el folleto de Jean Czynski El Porvenir de las Mujeres, al que añadió un texto propio «Una palabra a las españolas». Elorza considera con este escrito el inicio de la propaganda feminsita en la provincia, frecuentemente teñida de tintes fourieristas -si bien Czynski adopta un orden universal más promatrimonial que Fourier- aunque el opúsculo de Morla apenas si habla del tema feminista. En concreto intenta mostrar lo positivo del trabajo atractivo, a las clases ricas y acomodadas, animando incluso a la Reina Isabel II a promover experiencias falansterianas. Así, frente a sectores más radicales del fourierismo, opta por un respeto a las estructuras existentes, sin perjuicio a las leyes religiosas, morales y políticas. V. ELORZA, A., El Fourierismo en España, Madrid, 1975 y MALUQUER DE MOTES, J., El socialismo en España 1833-1868, Barcelona, 1977.

(3) Esta última posibilidad de dejar entreabierta la realidad matrimonial, empuja a Elorza a sostener que la concepción de la moral de éste, es más conformista que la de su maestro, pues reduce la independencia de la mujer, a una educación igual y a la libre elección en el matrimonio, con lo que regresa de nuevo a las limitaciones de partida. La apreciación no es desde luego descaminada. V. ELORZA, op. cit., p. XLII.

(4) El Nacional, 17, 18 y 20 dic. 1841. En el mismo periódico y entre los años 1841 y 1842 , localizamos hasta diez artículos más de su pluma, en los que desarrolla un modelo de sociedad liberal, constitucional y demócrata, ante los nuevos acontecimientos revolucionarios y contrarrevolucionarios en Europa.

(5) Dirigida por la escritora Margarita Pérez de Celis, colaboraron otras mujeres como María José Zapata, Rosa Butler y en menor medida Adela Peña, Joaquina 
García Balmaseda, Francisca González y Ruiz, Angela Arizu y María de Zamora. V. FAGOAGA, C., La voz y el voto de las mujeres. El sufragio en España (1877-1931), Barcelona, 1985, p. 50.

No obstante y remitiéndonos a los esporádicos reflejos de mujeres en la prensa, no deja de llamar la atención el aparecido en El nacional 27 jul. 1854, bajo el título de «Una mujer». Esta carta escrita a los pocos días del triunfo revolucionario, sugería una peculair reivindicación:

«Habiendo toda la nación alzado el grito de libertad, es extraño que en esta ciudad donde hay tantos liberales, estemos nosotros sufriendo un despotismo nunca conocido, pues estando en Cádiz rodeado de mar es doloroso haciendo unos días de tanto calor, que solamente las mujeres estén privadas de lo que tanto abunda y sin dueño, pues al paso que vamos, van a abrir la Caleta para el mes de enero y haya poca concurrencia...por eso me valgo de la presente para suplicarle diga algo en El Nacional sobre el particular, en gracia a la feliz vuelta de los liberales al poder...»

(6) El Nuevo Pensil de Iberia, 10 oct. 1857, y 20 en. 1858, y El Pensil de Iberia, 10,20 y 30 de abril, y 10 y 20 de mayo 1859.

(7) El Nuevo Pensil de Iberia, 20 jul. 1858.

(8) La Buena Nueva, 15 dic. 1865.

(9) V. Revista Gaditana, 30 jul, 8 sep. y 30 nov. 1867, y 16 en. 1868.

(10) Ibidem.

(11) Ibidem.

(12) Ibidem.

(13) Ibidem, 8 ag., 8 sep. y 30 nov. 1867, y 8 mar. 1868.

(14) Ibidem.

(15) Otro tema de matiz social y variante feminista, son los respectivos a la infidelidad como realidad recogida en el seno de la pareja burguesa, o la propia ostentación de la moda, burda apariencia que a las menos desahogadas, hace pasar apuros económicos. V. MARCHENA, J., «Fermín Salvochea en vísperas de La Gloriosa: una aproximación ideológica», Trocadero, Cádiz, Universidad, 1989, n. 1, pp. 161-176. 